\title{
Value System Redesign: System oriented management and enterprise integration in globally distributed manufacturing networks
}

\author{
B. R. Katzy \\ Dr.-Ing. Dipl.-Kfm., research officer, lecturer \\ University St. Gallen, Institute of Technology Management, \\ Unterstrasse 22, 9000 St. Gallen, Switzerland, \\ Tel. (Fax): 0041-71-2282450 (420), \\ e-mail: Bernhard.Katzy@item.unisg.ch

\section{B. Riggers} \\ Dipl.-Wirtschafts-Ingenieur \\ University St. Gallen, Institute of Technology Management, \\ Unterstrasse 22, 9000 St. Gallen, Switzerland, \\ Tel. (Fax): 0041-71-2282450 (420), \\ e-mail: Bernd.Riggers@item.unisg.ch
}

\begin{abstract}
The paper will propose a way to augment „knowledge and appreciation of integrated systems“ for the purpose of the integration of globally distributed manufacturing sites. The objective is to provide an ,associated methodology“ for managers in industrial enterprises, responsible for the design and operation of globally distributed manufacturing networks and their providers for business process re-engineering, ICT-infrastructures and logistics services. We introduce a strategic level of the enterprise system as a completion to the existing operative Enterprise Integration Architectures.
\end{abstract}

Keywords

CIMOSA, Enterprise integration, ICT-infrastructure, logistics, manufacturing, modelling, network, process re-engineering, strategy, TELEflow, value system, virtual 


\section{INTEGRATION IN THE IFIP/IFAC WORK}

In the first Workshop on DIISM in Tokyo 1993, ,a possible road map for promotion of the field of enterprise integration" (Williams 1993) has been defined. The paper will propose a way to augment „knowledge and appreciation of integrated systems“ not for ,potential users everywhere" but for the purpose of the integration of globally distributed manufacturing sites. The objective is to provide an ,associated methodology“ for that concerned „user application group". They are managers in industrial enterprises, responsible for the design and operation of globally distributed manufacturing networks and their providers for business process reengineering, ICT-infrastructures and logistics services. We introduce a strategic level of the enterprise system as a completion to the existing operative Enterprise Integration Architectures.

\section{THE PROJECT}

This paper will present the concept and first findings of the TELEflow-project. The TELEflow-project has been selected as ,flagship project" for the telematics application program in the 4th framework. Its objective is to develop methods and tools for business process reengineering in global manufacturing networks applying advanced telematics technologies. It was officially started in February 1996. It has a duration of three years. Partners are ATM from Daimler Benz (D), Danzas (CH), GPS (D), Huber und Suhner (CH), Intracom (GR), Siemens Nixdorf (CH), TRD (GR) and University St. Gallen (CH).

\section{THE CASE}

The case is derived from one of the three pilot sites in the TELEflow-project where infrastructure services are designed and installed.

\subsection{The situation}

The company is a mediumsized, high quality provider of electrotechnical equipment for highfrequency installations such as antennas, HF-connectors and cables. The equipment is used for example in the basis stations for mobile telephone networks. The networks are provided e.g. by Motorola, Ericsson or Nokia who are customers. In 1995 turnover increased by 10,8 \%, which was mainly carried by an increase of exports from $58 \%$ to $67 \%$ (N.N.(Gruppenertrag) 1996). Another positive news for 1995 was the start of manufacturing in England, Canada and Singapore (N.N. (Ertrag) 1996).

\subsection{The requirements}

Existing linear models of business processes (figure 1, left side) that are focused on the customer and provided by distribution partners (A), manufacturing (B) and suppliers (C) have to be amended as to cope with the new business situation. First, because customers have to be served at globally distributed sites with the same quality, service and conditions. 


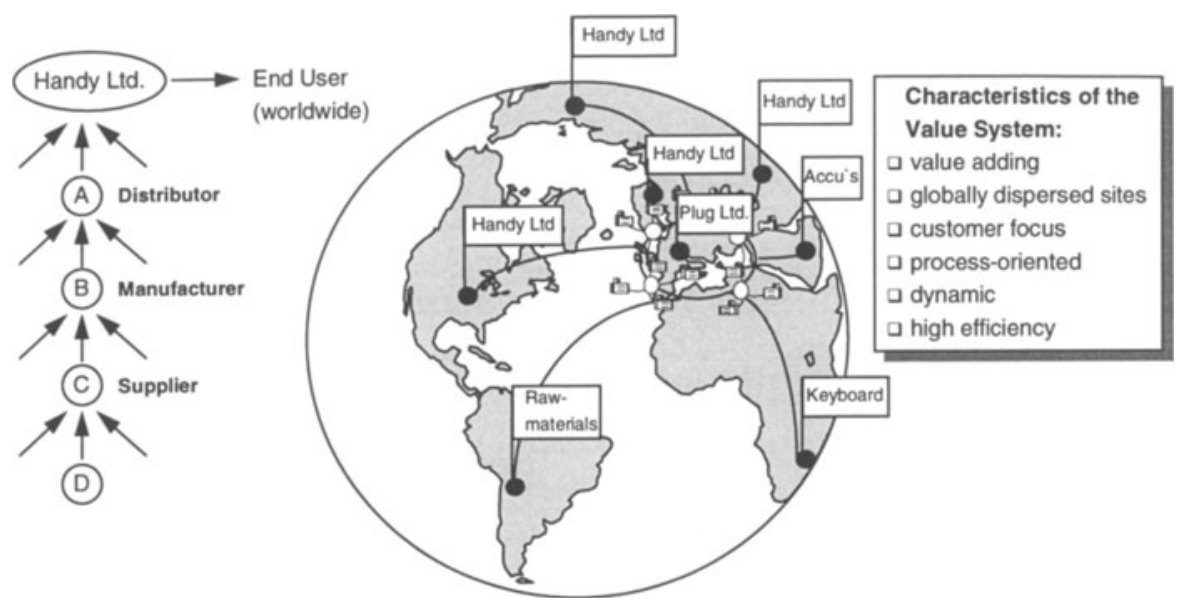

Figure 1 Example of a value system

Second as the business situation shows manufacturing is no longer concentrated to one site, instead now there are four sites (bullet B) to be regarded in the process chain. The linear value chain such changes to a network structure of involved partners (figure 1, right side). The partners can be different units of the company or independent business partners. We named this network a value system, as it is designed to create added value for the customer.

\section{One holistic Value System - Three Views}

\section{One Value System}

\section{Three Views}

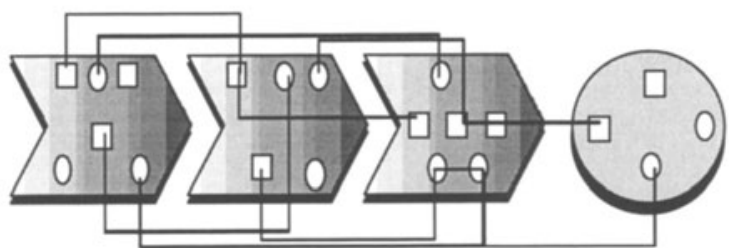

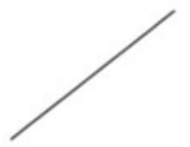

Processes

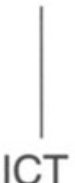

ICT

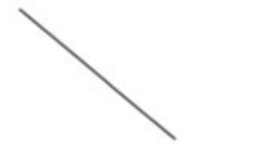

Logistics

Figure 2 Relevant views on the value system

Business processes within the value system have to perform as efficient as those inside one corporation. As we focus on manufacturing industries logistics services are an important aspect of the value system, as its total cost today amounts to $10-25 \%$ of the total product cost 
(Schuh 1996). Information and Communication Technologies (ICT) provide the third important aspect of the value system infrastructure.

Advanced technologies in all three disciplines, business process re-engineering, logistics and ICT, exist, but there is a need to harmonise those three independent systems in order to achieve the required efficiency (figure 2).

Systems theory is referred to in all three disciplines. In our experience this is as much a chance as it is a challenge! Today's challenge is the very different application of the systems theory principles behind the same terms. „Behaviour“ for example that is modelled within ITsystem design to control the dynamic invocation of functional operations for business managers describes pure ,soft factors“ and is restricted to people. In fact misunderstandings are a major obstacle to the harmonisation of the different solutions. On the other hand the chance of a systems approach in our eyes lies in the integration of the existing solutions for a business application. But this requires a clear conception of the value system.

Industrial users like the case presented as well as service providers for ICT or logistics face the same need to understand the value system. The former as they have to design and operate their value system, the latter as they have to create and demonstrate the added value of their services as integrated parts of a value system.

\section{THE VALUE SYSTEM}

Tomorrow's competition will no longer take place among single companies, but among value systems. A value system (VS) is the organisation of all companies (e.g. different sites, supplier, OEM, Distributor, Service Provider) that collaborate for the customer solution (figure 3).

\section{Definition of the Value System:}

A Value System is a focused network of companies and units,

in order to maximize the added value created,

by optimizing the intercompany value chains.

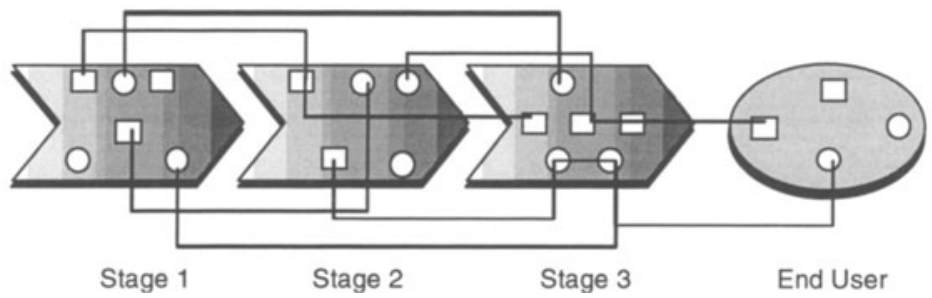

Figure 3 Definition value system 


\section{1) The strategic level of the value system}

This definition deliberately includes the ,what is the value system for?". This is to point out that the value system describes the application technologies and the allocation of people or organisations in a competitive environment. Generating superior value for the stakeholders is the reason for the value system to exist and the entire network is focused on this. Necessary elements of the entirely human oriented strategic level of the value system are derived from the analysis of what is necessary to achieve superior value for the customer.

\section{2) The operative level of the value system}

„What does the value system look like?" is the description of the infrastructure of the network throughout the system life cycle in terms of requirements that it has to fulfil, its design and implementation.

\section{3) Integrated management of the value system}

A value system is a consortium of interacting, legally independent companies and units. Value systems have to be managed to sustain competitiveness. They have to be designed, operated and continuously improved in dynamic environments. This means to broaden the domain of interest for manufacturing management and to actively re-engineer inter-company-processes of the value system. Methodologies are needed for this value system management of a fluid or flexible network organisation in a highly dynamic environment. The management of such a Value System faces the challenge to gain a fit between operative and strategic level.

\section{THE VALUE SYSTEM FRAMEWORK}

\subsection{Dimensions}

The framework has been defined to find a linking structure across the traditional three views and the strategic and operative level. It is intended to provide a concept that allows managers (1) to structure the complexity of the VS, (2) to understand their roles in the VS and (3) to support pro-active decision making in the VS. Three relevant dimensions of the VS framework $^{1}$ have been fixed to cope with the needs of the VS management (figure 4):

\footnotetext{
${ }^{1}$ in analogy to Bleicher (1995)
} 


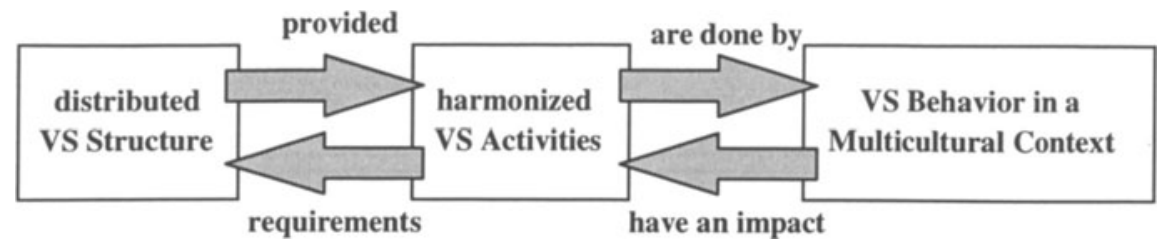

- Stable network structure engineered by suppliers

$$
\begin{gathered}
\text { - Dynamic usage by } \\
\text { industrial partners }
\end{gathered}
$$

- Experts for Logistics, ICT, Processes - people form different countries or companies

Figure 4 Dimensions of the value system

As the challenge of competitive VS will be the integration of geographically distributed sites and companies (as a specific form of a virtual organisation) the distributed structure of this network is a first important dimension of the value system. Where the distributed structure is predominant for the providers of infrastructures (i.e. the ICT components) harmonised activities of the value system such as successful order processing or harmonised marketing programs are predominant for the industrial user. Global value systems require the collaboration of people from different companies, different countries and the three disciplines. The behaviour in a multicultural context has been stated by managers as one of the most critical success factors for the performance of value systems.

As this conference focuses on information infrastructures that we take as a part of the distributed structure of the value system I will step into detail on this first dimension, keeping in mind that there are close interdependencies with the two others.

\subsection{Profiles as a strategic description of the value system}

\section{Systems design as operative implementation of a value system}

Architectures for the integration of manufacturing enterprises provide a broad variety of constructs to describe different components of the distributed structure of a value system. Among others these are the Information System (ARIS) (Scheer 1991), the Decision System (GRAI) (Doumeingts 1987), the Organisation (CIMOSA) (Zimmermann 1995), Business Processes (ARIS, CIMOSA) and communication (CORBA) (Ben-Natan 1995). It is our intention to use these constructs to model the infrastructure components of the value system.

\section{Business concept or strategic design of a value system}

But we found that managers in value systems face the problem to integrate and harmonise existing (and mostly diverging) structures inside the partner companies. As it is normally impossible (to expensive or takes too much time) to implement new structures from scratch, it is necessary to find similarities between the existing structures which serve as leitmotivs to integrate them in a value system. Or, it can be foreseen that an integration may probably not produce synergies. We call these key characteristics the value system profiles (fig. 5). From interviews we identified the four given aspects concerning the distributed structure of a value system. They summarise the main perception of a Value System by managers in charge. We 
use portfolio techniques to visualise the profile, because managers are accustomed to it. This top down profile can be refined by a set of detailed criteria. Managers have perceived the information policy (lower left corner) within their value system between the extremes fully „transparent“, where information is accessible to every employee, or „task oriented“, where information is used as an instrument of power, on the other side. Certainly there are many forms in-between the extremes that we currently describe by examples and statements. We don't use figures to let the value system be described (50\% transparent, 50\% task oriented), because they are unsuitable and not meaningful enough. The description of such a profile requires many interviews, so that this refinement has to be seen as an ongoing process.

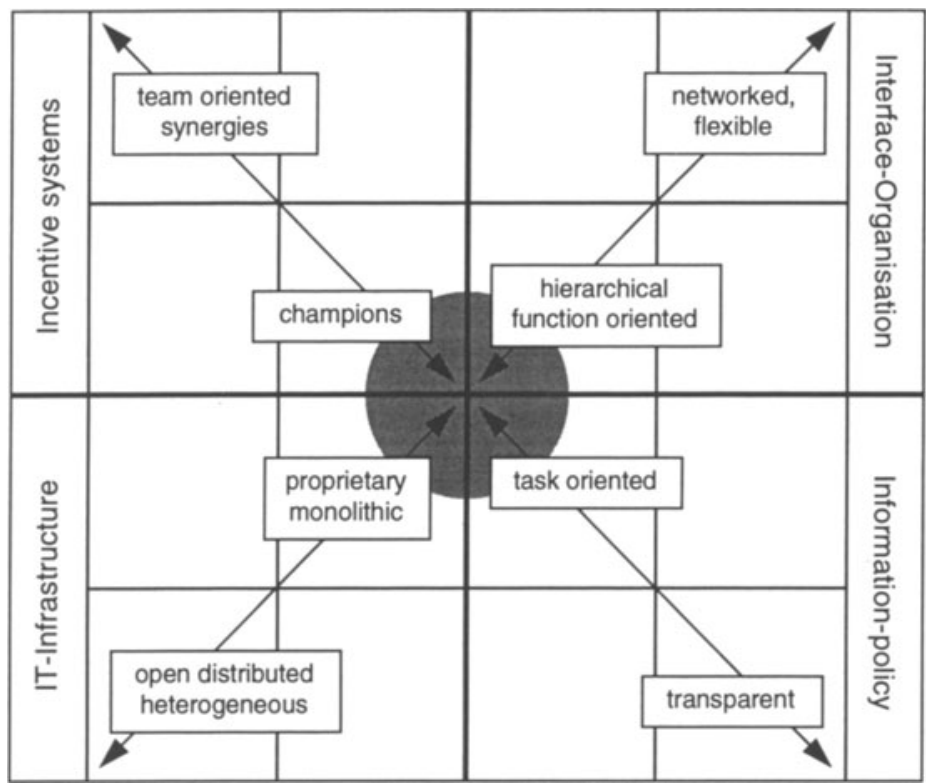

Figure 5 Profiles for value systems: Example for distributed structure

Industrial users may use this to assess the situation of their value system, identify the conflicts and derive the requirements for actions to be taken and structures to be implemented.

\section{SYSTEM INTEGRATION OF THE VALUE SYSTEM USING ENTERPRISE MODELLING TECHNIQUES}

Value system management can be supported by enterprise modelling techniques. The framework has been designed as a complement to the requirements definition level to extend the system life cycle into „earlier“ phases of business integration of the strategic level of the VS. As our first experiences show the industrial applicability of enterprise modelling techniques has been augmented with this framework. In our experience this is due to the fact that with this framework industrial managers are addressed as an own user group. 
We feel encouraged to this work as we interpret several indications within existing enterprise integration architectures as the expression of a need for such frameworks. Among others these are the „Enterprise View“ within ODP-CORBA (Ben-Natan 1995), the installation of a „Business Object Management Special Interest Group“ within OMG (Wagner 1996) or the recommended work on „enterprise integration methodologies“ with CIMOSA (Kosanke 1995). But this actual work still needs a clear reference point for the development of solution. For the value system framework we decided to search for this solution from a strict application point of view. Mature technologies will be looked at from this application point of view.

In order to deal with the differences to the existing enterprise modelling architectures intend to keep the specifications of the value system framework as a distinct ,strategic level“" (fig. 6).
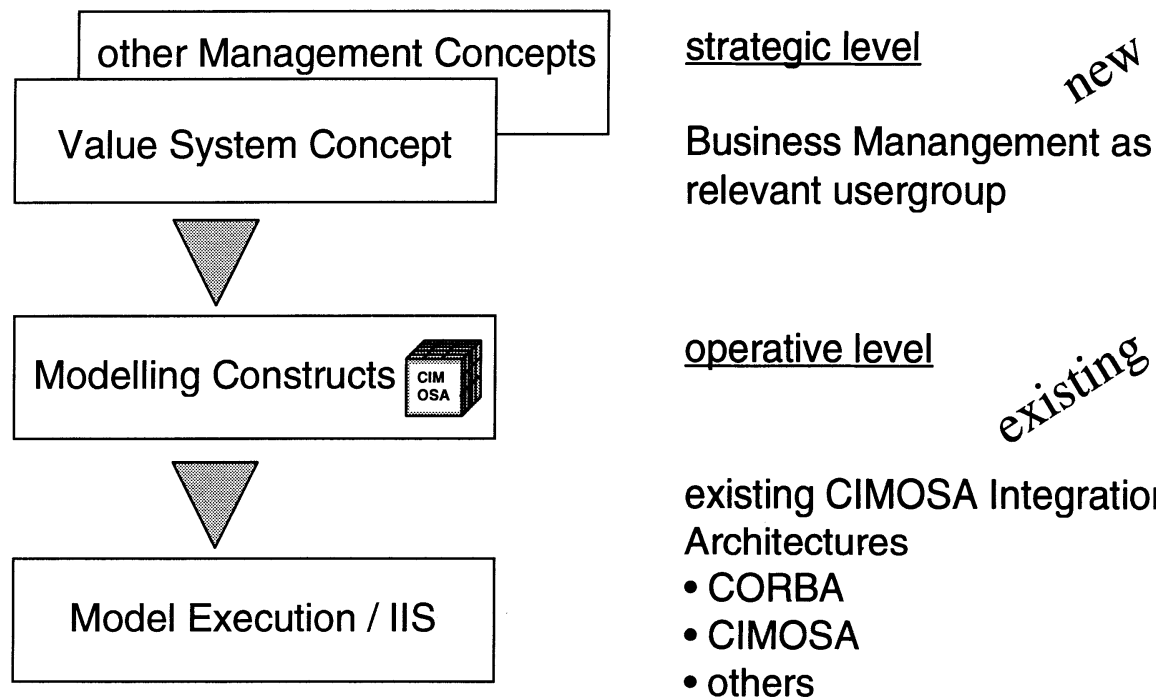

operative level

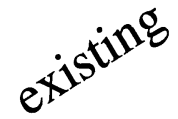

existing CIMOSA Integration

Architectures

- CORBA

- CIMOSA

- others

Figure 6 Strategic level and enterprise integration architectures

\section{Differences in Modelling}

A first difference of the strategic level is the focus on the contents rather than on the formal correctness of the constructs applied. Consistency is measured by the credibility of the conception of the value system.

A second difference we discovered was the indicative character of the strategic level in contrary to the descriptive character of most existing enterprise modelling architectures. The objective is to create a shared conception of the value system between the business managers involved. This difference leads e.g. to a different definition of what is complete. The strategic level is regarded as complete when nothing can be skipped without loosing the essential idea of the concept. Additional details in the best case are regarded as superfluous, mostly as misleading and often as tutelage. As most partners volunteer to participate in the value system they have to be motivated by a strong idea of the value system to bring in their own decentral solutions for the common purpose. Detailed centralised value system models in this sense are dysfunctional as they are perceived as an attempt for order and control. 
Object oriented techniques fulfil the requirements of decentral co-ordination. For ,managed objects" it can be negotiated (for all people, organisational units or infrastructure components) what is public in the value system and what remains private. On the other side the object oriented approach allows for the integration with existing modelling techniques.

Other time-tested concepts from enterprise integration like the instantiation process will be kept for the operative level. A ,generic" value system as a general conception of what a value system is, will be described to step forward to best practice or benchmark descriptions as „partial models“ and to provide for the design of individual or „particular" value systems ${ }^{2}$ during the work of the TELEflow project. Based on the application of existing methods and tools the integration concept for the value systems is enhanced by three operative instruments. First, a process reengineering method for inter-company processes in value systems is developed. Second, a method to map business process specifications into the communication system architecture is adopted from CORBA. Third, on the basis of stable business process modelling of enhanced logistics solutions will be supported.

\section{CONCLUSIONS}

Based on existing technical solutions in the three disciplines business process re-engineering, logistics and ICT the presented user driven concept of the value system has been developed to guide the integration of value systems in the TELEflow-project. Following the expressed business needs of the industrial partners existing enterprise modelling architectures (e.g. CIMOSA for business process modelling and CORBA for the design of communication transparency platforms) have been enhanced by a ,strategic level“ to express the conception of the value system and bridge the gap to the (technical) system life cycles. Even in this early stage of the work this has proven to be an important ,interpreter" between ,user needs" and „technical providers“.

\section{8}

\section{REFERENCES}

Bleicher, K. (1995) Das Konzept Integriertes Management. Campus Verlag, Frankfurt Ben-Natau, R. (1995) CORBA - A guide to C.O.R.B.A. McGraw-Hill, New York

Doumeingts, G. et al. (1987) Design Methodology for advanced manufacturing systems. Computers in Industry, Nr. Oct., p.271-296

Esprit Consortium AMICE (1993) CIM Open System Architecture. Springer Verlag, Berlin

Kosanke, K. (1995) CIMOSA - Overview and status. Computers in industries, 27, p. 101-109, Elsevier Science B.V., Amsterdam

N.N. (2.2.1996) Höherer Gruppenertrag von Huber und Suhner. Neue Zürcher Zeitung

N.N. (2.2.1996) Huber und Suhner mit durchwachsenem Ertrag. St.Galler-Tagblatt

Scheer (1991) Architektur integrierter Informationssysteme: Grundlagen der Unternehmensmodellierung. Springer Verlag, Berlin

\footnotetext{
${ }^{2} \mathrm{cf}$ the model instantiation process, Esprit Consortium AMICE (1993)
} 
Schuh, G. (1996) Logistikmanagement - Strategische Wettbewerbsvorteile durch Logistik. Schuh, G., et al. (Ed.), Logistikmanagement, Schäffer Poeschel, Stuttgart, p.V. V-VIII

Wagner, M. (1996) Die Entwicklung von Business-Objekten steckt noch in den Kinderschuhen. Computer Zeitung, Nr.8.

Williams, T.J. et al., (1993) Architectures for Integration Manufacturing Activities and Enterprises. Yoshikawa, H. et al., Information Infrastructure Systems for Manufacturing, Amsterdam.

Zimmermann, H. (1995) Potentiale der integrierten Organisationsmodellierung in produzierenden Unternehmen. Dissertation St.Gallen, Hallstadt

\section{BIOGRAPHY}

\section{Dr.-Ing. Dipl.-Kfm. Bernhard R. Katzy}

born on April 9th, 1962 in Aachen

started his professional career as a car mechanic. Later he studied Electronics and Business Management at the Technical University of Aachen.

After his PD on „Modelbased Enterprise Engineering for Manufacturing“ he joined the Institute of Technology Management in 1994 as Research Officer and Lecturer at the University St. Gallen.

\section{Dipl.-Wirtschafts-Ingenieur Bernd Riggers}

born on December 12th, 1965 in Hamburg, Germany

after finishing his studies in business administration and mechanical engineering at the Technical University Berlin in 1993 he worked for a consulting company in the fields of system analysis and business process reengineering. In October 1993 he moved to St. Gallen to start his $\mathrm{PhD}$-Thesis, in the field of agile manufacturing networks and value system redesign, at the Institute for Technology Management at the University of St. Gallen, Switzerland. Actually he is project leader of the European research project TELEflow, which has the objective to provide companies with a holistic management concept for designing and operating interorganisational networks. 